\title{
Current perspectives on intrathecal drug delivery
}

This article was published in the following Dove Press journal:

Journal of Pain Research

6 November 2014

Number of times this article has been viewed

\author{
Michael M Bottros' \\ Paul J Christo ${ }^{2}$ \\ 'Division of Pain Medicine, \\ Department of Anesthesiology, \\ Washington University School of \\ Medicine, St Louis, MO, ${ }^{2}$ Division \\ of Pain Medicine, Department of \\ Anesthesiology and Critical Care \\ Medicine, The Johns Hopkins \\ University School of Medicine, \\ Baltimore, MD, USA
}

Correspondence: Paul J Christo Division of Pain Medicine, Department of Anesthesiology and Critical Care Medicine, The Johns Hopkins University School of Medicine, Suite 30I Baltimore, 550 North Broadway, MD, 21205, USA Email pchristo@jhmi.edu

Michael M Bottros

Division of Pain Medicine, Department of Anesthesiology, Washington University School of Medicine, Campus Box 8054, 660 South Euclid Ave, Saint Louis, MO, 63110-1093, USA

Email bottrosm@anest.wustl.edu

\begin{abstract}
Advances in intrathecal analgesia and intrathecal drug delivery systems have allowed for a range of medications to be used in the control of pain and spasticity. This technique allows for reduced medication doses that can decrease the side effects typically associated with oral or parenteral drug delivery. Recent expert panel consensus guidelines have provided care paths in the treatment of nociceptive, neuropathic, and mixed pain syndromes. While the data for pain relief, adverse effect reduction, and cost-effectiveness with cancer pain control are compelling, the evidence is less clear for noncancer pain, other than spasticity. Physicians should be aware of mechanical, pharmacological, surgical, and patient-specific complications, including possible granuloma formation. Newer intrathecal drug delivery systems may allow for better safety and quality of life outcomes.
\end{abstract}

Keywords: pain control, intrathecal analgesia, drug delivery systems

\section{Introduction}

In 1999, the Joint Commission on Accreditation of Healthcare Organizations issued comprehensive standards of care for pain management. It stated, "No cancer patient should live or die with unrelieved pain". ${ }^{1}$ The World Health Organization established a simple three-step "ladder" approach in 1986, beginning with nonopioid drugs and progressing to stronger opioids as necessary. Adjuvant drugs, such as anticonvulsants and antidepressants, may also be used at each step, as follows: patients who are receiving no analgesic therapy should receive nonopioid analgesic drugs, including nonsteroidal anti-inflammatory drugs (step 1); if the pain is not adequately treated, persists, or increases despite therapy with nonopioid medications, the dose of the nonopioids should be increased and mild opioid analgesic drugs may be added (step 2); and for increasing or persistent pain, or moderate-severe pain at the outset, strong opioids such as morphine may be used (step 3).

Few medical guidelines have made such an impact on health care as the World Health Organization pain ladder, so much so that it has been unofficially applied for use in other pain syndromes, including chronic nonmalignant pain. Patients receiving adjuvant therapy and oral or transdermal opioids achieve adequate pain control in approximately $80 \%$ of cases. However, in $20 \%$ of patients, some form of alternative or invasive therapy is needed to control recalcitrant pain despite aggressive titration of these medications along the World Health Organization ladder. Adverse effects of opioids may also prevent patients from achieving maximal benefit. ${ }^{2}$ For example, gastrointestinal side effects, including both constipation and nausea, are estimated to range as much as $10 \%-40 \%{ }^{3}$ In 1994, as part of the Mayo Clinic symposium on pain management, the World Health 
Organization ladder was extended to include interventional pain therapies, such as spinal analgesia, nerve stimulation, and neurolytic blocks. ${ }^{4}$ This "fourth step" of the analgesic ladder has provided practitioners with an indispensable means of pain control for patients suffering from refractory pain. This article focuses on one of these interventional treatments, namely intrathecal drug delivery.

\section{History of intrathecal analgesia and intrathecal drug delivery systems}

In 1898, soon after the discovery of cocaine as a local anesthetic, August Bier documented the first spinal analgesia by injecting cocaine into his own intrathecal space as well as that of six patients who were to undergo lower extremity surgery, thus creating immense interest in this technique. ${ }^{5}$ Soon after, Rudolph Matas showed that mixing morphine with cocaine was able to mitigate the adverse symptoms associated with intrathecal cocaine. ${ }^{6}$ Continuous spinal analgesia was first used in the 1940s, but it was the discovery of opiate receptors in the spinal cord in 1973 that provided a scientific rationale for this form of treatment. ${ }^{7}$ The development of infusion pumps in the early 1970s allowed for greater flexibility in administering intrathecal opiates. ${ }^{8}$ For example, Wang et al first reported the successful use of intrathecal morphine for the treatment of intractable cancer pain in $1979 .{ }^{9}$ Two years later, the first use of an implantable intrathecal drug delivery system (IDDS) was reported. ${ }^{6}$ During the 1980 s, this form of drug delivery provided a fixed continuous infusion rate, allowing physicians to use lower doses of analgesics and thus decreasing adverse effects such as sedation and constipation. Changing the dose could only be performed by aspirating the medication from the pump reservoirs and refilling them with a different concentration of the medication. ${ }^{10}$ These dose changes introduced the inherent risks associated with frequent aspiration and injection of these solutions, such as infection and inadvertent deposition of the solution outside the reservoir, leading to potential systemic overdose. In 1991, externally programmable, battery-powered IDDS pumps were introduced, allowing for noninvasive dose changes of these medications using an external programmer. ${ }^{10}$ This allowed for an easier means of changing patients' analgesic therapies in response to the dynamic changes in pain. ${ }^{11}$

\section{Indications for intrathecal drug delivery and patient selection criteria}

There are no universally accepted guidelines or recommendations for patient selection. In general, patient selection for IDDS therapy can be divided into cancer and noncancer pain. In both groups, patients suffering from significant side effects of oral, transdermal, or intravenous opioids that inhibit adequate titration of these medications or those patients who cannot achieve adequate analgesia despite high doses of opioids should be considered for intrathecal therapy. Several other factors should be included when considering the patient for intrathecal drug delivery, such as previous adherence to treatment, ability/willingness to attend for follow-up, and anatomical changes that may affect implantation of either the pump or catheter. The patient's disease state, failure of conservative therapy, psychological state, adherence to treatment, and candidacy for a surgical procedure all reflect important considerations prior to possible implantation. ${ }^{12}$

Indications for the use of IDDS in chronic noncancer pain typically include pain originating from the spine and, specifically, patients with failed back surgery syndrome primarily, followed by compression fractures, spondylosis, spondylolisthesis, and spinal stenosis. Other conditions include spinal cord injury-induced spasticity, complex regional pain syndrome, chronic pancreatitis, neuropathies, and rheumatoid arthritis. ${ }^{13}$ Patients with chronic noncancer pain being considered for IDDS must undergo a thorough evaluation for psychiatric comorbidities such as depression, anxiety, addiction, suicidal ideation, or personality disorders, since the presence of these have been associated with a poor response to intrathecal therapy. ${ }^{14}$

Several studies have shown the benefits of IDDS in patients with cancer pain. ${ }^{15,16}$ Previous studies and reviews have considered including only patients who have a life expectancy of at least 3 months. ${ }^{17}$ However, the Polyanalgesic Consensus Committee (PACC) revised their recommendations in 2012, stating that previous recommendations for the placement of pumps only in patients with greater than 3 months of life expectancy was based on antiquated data. ${ }^{18}$ Deer et al feel that life expectancy may be increased with intrathecal therapy because of reduced side effects, suggesting that, in the absence of impending death, IDDS should be considered even if a patient's prognosis falls short of 3 months. ${ }^{19}$ With improved pain control and fewer adverse effects, an enhanced survival seems probable. However, at 6 months post-implantation, Smith et al showed that IDDS only trended toward significance $(53.9 \%$ for IDDS versus $37.2 \%$ for control, $P=0.06) .{ }^{15}$ Patients undergoing chemotherapy or radiation should also be considered for IDDS. Smith et al further showed that patients could endure more aggressive chemotherapy/radiation treatment due to the decreased adverse effects associated with IDDS medications when 
compared with conventional forms of pain management. ${ }^{15}$ Indications with reasonable evidence for support of IDDS therapy include failed back surgery syndrome, and select patients with diabetic peripheral neuropathy, complex regional pain syndrome, and spasticity. Patients with these conditions can benefit the most from IDDS therapy.

IDDS is contraindicated in patients who: are unable/ unwilling to have the pump refilled, have significant coagulopathies, require therapeutic anticoagulation, are hemodynamically unstable, have spinal cord pathology with cerebrospinal fluid outflow obstruction, have intracranial hypertension, have sepsis, have an infection at the site of the catheter or pump insertion, have significant emaciation preventing implantation of the device, or have significant psychiatric comorbidities. ${ }^{20}$

\section{Intrathecal medications}

Currently there are only three medications approved by the US Food and Drug Administration (FDA) for use via the intrathecal route, ie, morphine, ziconotide, and baclofen. Morphine targets opioid receptors within the dorsal horn. It is considered by many to be the gold standard intrathecal opioid agonist, against which all other opioids are compared. Morphine binds to receptors on the primary afferent neurons (presynaptic) and cells within the dorsal horn of the spinal cord (postsynaptic) to inhibit the release of neurotransmitters like substance $\mathrm{P}$ and calcitonin gene-related peptide and hyperpolarize postsynaptic neurons, respectively. Ziconotide provides analgesia by blocking specific $\mathrm{N}$-type calcium channels found at presynaptic terminals in the dorsal horn.

Baclofen is a gamma-aminobutyric acid (GABA)-B agonist acting on both presynaptic sites (decreasing calcium conduction resulting in decreased excitatory amino acid release) and postsynaptic sites (increasing potassium conductance leading to neuronal hyperpolarization). Baclofen inhibits sensory input to the motor neurons of the spinal cord. It is used to treat muscle spasms, spasticity, and neuropathic pain. While these three medications are the only FDA-approved drugs to be used intrathecally, in practice, other medications, such as clonidine, bupivacaine hydromorphone, fentanyl, and sufentanil are also used. In fact, the PACC outlined their most recent recommendations on drug choice, concentration limits, and recommended starting dosages in their 2012 guidelines. ${ }^{18}$ Their medication recommendations are based on the type of pain that the patient exhibits. For instance, Table 1 presents recommendations based on neuropathic pain management while Table 2 presents recommendations based
Table I 2012 Polyanalgesic Consensus Committee recommendations for intrathecal medication in neuropathic pain management

\begin{tabular}{|c|c|c|c|}
\hline Line I & Morphine & Ziconotide & $\begin{array}{l}\text { Morphine }+ \\
\text { bupivacaine }\end{array}$ \\
\hline Line 2 & Hydromorphone & $\begin{array}{l}\text { Hydromorphone } \\
+ \text { bupivacaine or } \\
\text { Hydromorphone + } \\
\text { clonidine }\end{array}$ & $\begin{array}{l}\text { Morphine + } \\
\text { clonidine }\end{array}$ \\
\hline Line 3 & Clonidine & $\begin{array}{l}\text { Ziconotide + opioid } \\
\text { Fentanyl }\end{array}$ & $\begin{array}{l}\text { Fentanyl + } \\
\text { bupivacaine } \\
\text { or Fentanyl } \\
+ \text { clonidine }\end{array}$ \\
\hline Line 4 & $\begin{array}{l}\text { Opioid }+ \text { clonidine }+ \\
\text { bupivacaine }\end{array}$ & $\begin{array}{l}\text { Bupivacaine }+ \\
\text { clonidine }\end{array}$ & \\
\hline Line 5 & Baclofen & & \\
\hline
\end{tabular}

Notes: Line I: Morphine and ziconotide are approved by the US Food and Drug Administration for IT therapy and are recommended as first-line therapy for neuropathic pain. The combination of morphine and bupivacaine is recommended for neuropathic pain on the basis of clinical use and apparent safety. Line 2: Hydromorphone, alone or in combination with bupivacaine or clonidine, is recommended. Alternatively, the combination of morphine and clonidine may be used. Line 3: Third-line recommendations for neuropathic pain include clonidine, ziconotide plus an opioid, and fentanyl alone or in combination with bupivacaine or clonidine. Line 4: The combination of bupivacaine and clonidine (with or without an opioid drug) is recommended. Line 5: Baclofen is recommended on the basis of safety, although reports of efficacy are limited. Copyright 2012. Reproduced from John Wiley \& Sons, Inc. Deer TR, Prager J, Levy R, et al. Polyanalgesic Consensus Conference 2012: Recommendations for the management of pain by intrathecal (intraspinal) drug delivery: report of an interdisciplinary expert panel. Neuromodulation. 2012;15:436-466. ${ }^{18}$

on nociceptive pain management. For patients with mixed pain states, the PACC left the decision-making process to the managing physician based upon the clinical scenario and adaptation of the appropriate algorithm. Table 3 presents the recommended daily starting dosages for these medications.

\section{Trialing protocol}

Trialing of intrathecal agents was previously considered to be the standard of care in evaluating a patient's response and potential side effects to therapy. Patients' responses to neuraxial medications were used to determine whether an IDDS pump should be implanted and to satisfy requirements for insurance company reimbursement. In 2012, however, the PACC revised their recommendations on trialing for intrathecal drug delivery, stating that trialing was debatable, specifically in patients with cancer pain. ${ }^{12}$ They acknowledged that a trial may underestimate potential side effects and the failure rate of IDDS therapy. Despite the opinion shift, it is generally recommended to consider a trial prior to implantation because it is currently the most demonstrative method of emulating a system that would eventually be implanted. Although trialing has been used for more than a decade, there is a dearth of studies that demonstrate the best method. ${ }^{12}$ The PACC 2012 expert panel provided a potential 
Table 22012 Polyanalgesic Consensus Committee recommendations for intrathecal medication in nociceptive pain management

\begin{tabular}{|c|c|c|c|c|}
\hline Line I & Morphine & Hydromorphone & Ziconotide & Fentanyl \\
\hline Line 2 & $\begin{array}{l}\text { Morphine + } \\
\text { bupivacaine }\end{array}$ & $\begin{array}{l}\text { Ziconotide + } \\
\text { opioid }\end{array}$ & $\begin{array}{l}\text { Hydromorphone }+ \\
\text { bupivacaine }\end{array}$ & $\begin{array}{l}\text { Fentanyl + } \\
\text { bupivacaine }\end{array}$ \\
\hline Line 3 & $\begin{array}{l}\text { Opioid } \\
\text { (morphine, } \\
\text { hydromorphone, } \\
\text { or fentanyl) + } \\
\text { clonidine }\end{array}$ & & Sufentanil & \\
\hline Line 4 & $\begin{array}{l}\text { Opioid + } \\
\text { clonidine }+ \\
\text { bupivacaine }\end{array}$ & & $\begin{array}{l}\text { Sufentanil + } \\
\text { bupivacaine or } \\
\text { clonidine }\end{array}$ & \\
\hline Line 5 & $\begin{array}{l}\text { Sufentanil + } \\
\text { bupivacaine + } \\
\text { clonidine }\end{array}$ & & & \\
\hline
\end{tabular}

Notes: Line I: Morphine and ziconotide are approved by the US Food and Drug Administration for IT therapy and are recommended as first-line therapy for nociceptive pain. Hydromorphone is recommended on the basis of widespread clinical use and apparent safety. Fentanyl has been upgraded to first-line use by the consensus conference. Line 2: Bupivacaine in combination with morphine, hydromorphone, or fentanyl is recommended. Alternatively, the combination of ziconotide and an opioid drug can be employed. Line 3: Recommendations include clonidine plus an opioid (ie, morphine, hydromorphone, or fentanyl) or sufentanil monotherapy. Line 4: The triple combination of an opioid, clonidine, and bupivacaine is recommended. An alternate recommendation is sufentanil in combination with either bupivacaine or clonidine. Line 5: The triple combination of sufentanil, bupivacaine, and clonidine is suggested. Copyright 2012. Reproduced from John Wiley \& Sons, Inc. Deer TR, Prager J, Levy R, et al. Polyanalgesic Consensus Conference 2012: Recommendations for the management of pain by intrathecal (intraspinal) drug delivery: report of an interdisciplinary expert panel. Neuromodulation. 2012;15:436-466. ${ }^{18}$

algorithm for intrathecal trials. After determining that a patient is a candidate for intrathecal pump implantation, the next step is to determine the trialing method based upon the type of pain the patient exhibits. If it is predominantly nociceptive pain, then consider using a single-shot intrathecal trial (single-shot epidural trials are not recommended by the panel). If the patient exhibits either neuropathic pain or a mixed pain state, then the clinician must determine whether or not the patient is able to tolerate a prolonged infusion. If the answer is yes, then consider either a morphine trial via epidural/ intrathecal infusion route or a ziconotide/baclofen intrathecal infusion trial. If the patient cannot tolerate a continuous

Table 3 Recommended starting dosage ranges of intrathecal medications

\begin{tabular}{ll}
\hline Drug & Recommended starting dosage \\
\hline Morphine & $0.1-0.5 \mathrm{mg} / \mathrm{day}$ \\
Hydromorphone & $0.02-0.5 \mathrm{mg} / \mathrm{day}$ \\
Ziconotide & $0.5-2.4 \mathrm{mcg} / \mathrm{day}$ \\
Fentanyl & $25-75 \mathrm{mcg} / \mathrm{day}$ \\
Bupivacaine & $1-4 \mathrm{mg} / \mathrm{day}$ \\
Clonidine & $40-100 \mathrm{mcg} /$ day \\
Sufentanil & $10-20 \mathrm{mcg} /$ day \\
\hline
\end{tabular}

Note: Reprinted with permission from Polyanalgesic Consensus Conference 2012: Recommendations for the management of pain by intrathecal (intraspinal) drug delivery: report of an interdisciplinary expert panel. Deer TR, Prager J, Levy R, et al. Neuromodulation. 15(5):436-466. ${ }^{18}$ Copyright @ 2012 John Wiley and Sons, Inc. infusion trial, then one may administer a bolus injection trial of morphine epidurally/intrathecally or ziconotide/ baclofen intrathecally. It is important to note, however, that manifestations of opioid-induced hyperalgesia or disease progression are difficult to assess from either a single-shot or infusion trial. ${ }^{12}$ Table 4 presents the recommended doses for intrathecal bolus trialing based upon the PACC 2012 recommendations. Pain relief, functional status, and adverse effects are observed during the trial. A 50\% decrease in pain, as well as a favorable side effect profile, are considered by many to be predictive of a successful IDDS implantation. ${ }^{21}$

\section{IDDS devices}

There are four methods of delivering medications intrathecally: two include the use of an external pump while the other two represent fully implantable devices. First, an external pump with a percutaneous catheter (tunneled or not tunneled) is less invasive to place and can be beneficial for patients with a limited life expectancy. Second, for patients with a short life expectancy, totally implanted catheters with a subcutaneous injection port connected to an external pump may be more suitable. These may also be used to conduct a prolonged trial.

Third, a fully implanted fixed-rate (or constant flow) IDDS may be beneficial for long-term delivery of analgesia. The Codman 3000 (Codman and Shurtleff, Inc., Raynham, MA, USA) is an example of such a system (Figure 1). Fixedrate delivery systems are less expensive than variable-rate delivery systems and do not require a battery to operate, so should theoretically last the lifetime of the patient. They generally possess a larger drug reservoir accommodating larger volumes and permitting longer time periods between refills. However, due to the constant flow nature of the system, it lacks the flexibility to change medication delivery or allow for a patient-controlled bolus.

The fourth method of spinal medication delivery consists of a fully implanted programmable IDDS, such as the

Table 4 Recommended doses for intrathecal (IT) bolus trialing

\begin{tabular}{ll}
\hline Drug & Recommended IT bolus dose \\
\hline Morphine & $0.2-1.0 \mathrm{mg}$ \\
Hydromorphone & $0.04-0.2 \mathrm{mg}$ \\
Ziconotide & $1-5 \mathrm{mcg}$ \\
Fentanyl & $25-75 \mathrm{mcg}$ \\
Bupivacaine & $0.5-2.5 \mathrm{mg}$ \\
Clonidine & $5-20 \mathrm{mcg}$ \\
Sufentanil & $5-20 \mathrm{mcg}$ \\
\hline
\end{tabular}

Note: Reprinted with permission from Polyanalgesic Consensus Conference 2012: Recommendations for the management of pain by intrathecal (intraspinal) drug delivery: report of an interdisciplinary expert panel. Deer TR, Prager J, Levy R, et al. Neuromodulation. 15(5):436-466. ${ }^{18}$ Copyright @ 2012 John Wiley and Sons, Inc. 

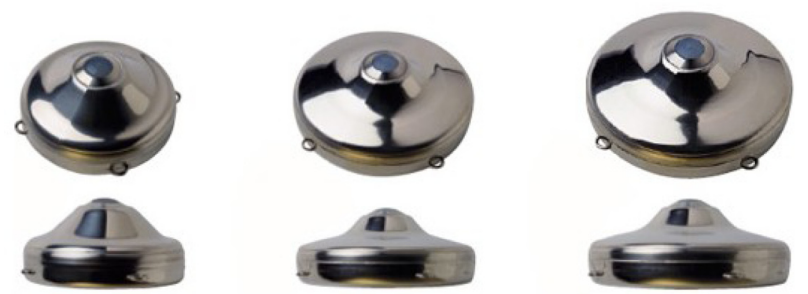

Figure I Codman 3000 intrathecal pump with progressively increasing reservoir sizes. Courtesy of Codman Neuro.

Medtronic SynchroMed II infusion system (Medtronic Inc., Minneapolis, MN, USA) (Figure 2). These programmable devices deliver either an intermittent or continuous amount of medication intrathecally. Drug dosages can be changed without intervention such as the aspiration and refilling of a different medication concentration as seen in fixed-rate delivery systems. Programmable dose changes are quite useful for conditions such as opioid tolerance or dynamic changes in pain that necessitate frequent dose alterations for patients with cancer. The pump can be interrogated or deactivated without emptying the drug reservoir in cases of suspected malfunction. However, because the system is battery driven, the life span of a pump is typically 4-7 years and requires surgical revision. Also, the refill interval is shorter (ie, more frequent) due to a smaller reservoir than those found in fixed-rate systems. The newest iteration of the SynchroMed II system includes the patient therapy manager. This is a handheld device that patients use to self-administer a dose of drug intrathecally, and thereby helps to address breakthrough pain. The software includes additional features, such as registering the visual analog pain scale before and after a bolus. These numbers are stored, analyzed, and used to reprogram the system for optimum dosing. A 2008 study looking at 168 patients found that $85 \%$ of patients were satisfied with this technology. ${ }^{22}$ The FDA recently approved a new programmable IDDS, the Prometra programmable pump
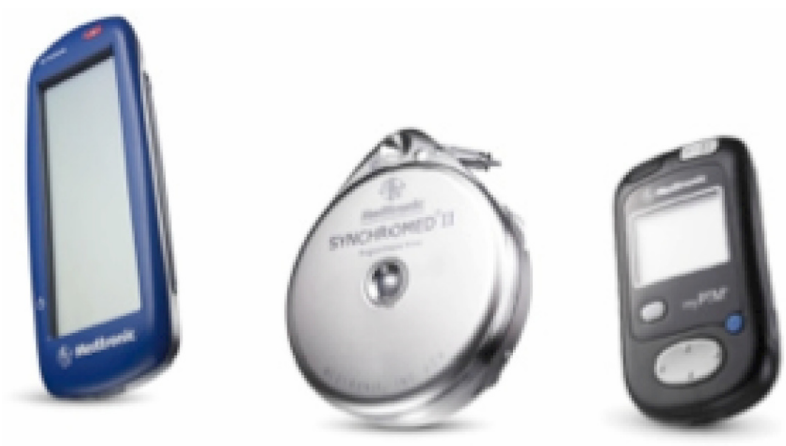

Figure 2 Medtronic SynchroMed II intrathecal pump, programmer, and patient therapy manager. Reprinted with the permission of Medtronic, Inc. (c) 2012. system (Flowonix Medical Inc., Mount Olive, NJ, USA) in February 2012 (Figure 3). This pump uses a valve-gated dose regulation system rather than the typical peristaltic pump roller system found in the Medtronic SynchroMed II. Rauck et al published the results of a trial evaluating the efficacy of this new system in administering intrathecal morphine in 110 patients with chronic pain. ${ }^{23}$ They found the mean accuracy of the pump to be $97.1 \%$ ( $90 \%$ confidence interval 96.2-98.0), which offers slightly improved accuracy when compared with the Medtronic SynchroMed II. Both the SynchroMed II and Prometra pumps are magnetic resonance imaging (MRI) compatible. However, the Prometra pump is only MRI compatible after complete removal of medication from the reservoir, whereas there is no need to remove medication from the SynchroMed II device. It is recommended to interrogate the SynchroMed II pump before and after MRI to ensure that the pump has properly reactivated following suspension of drug infusion during the MRI.

Other innovative infusion devices include the Medstream programmable infusion system (Codman and Shurtleff, Inc.), and the Medallion (Alfred Mann Foundation, Los Angeles, CA, USA). The Medstream system is currently only FDAapproved for the infusion of baclofen to treat spasticity. Its catheter design resists kinking and tearing, and uses compressed gas as the driving force as well as a ceramic drive flow valve system to maintain the infusion. Currently, Codman has stopped commercialization of the Medstream pump worldwide to focus on their core products within Codman Neurosurgery. The Medallion system awaits FDA approval. It incorporates a negative pressure reservoir, thus drawing

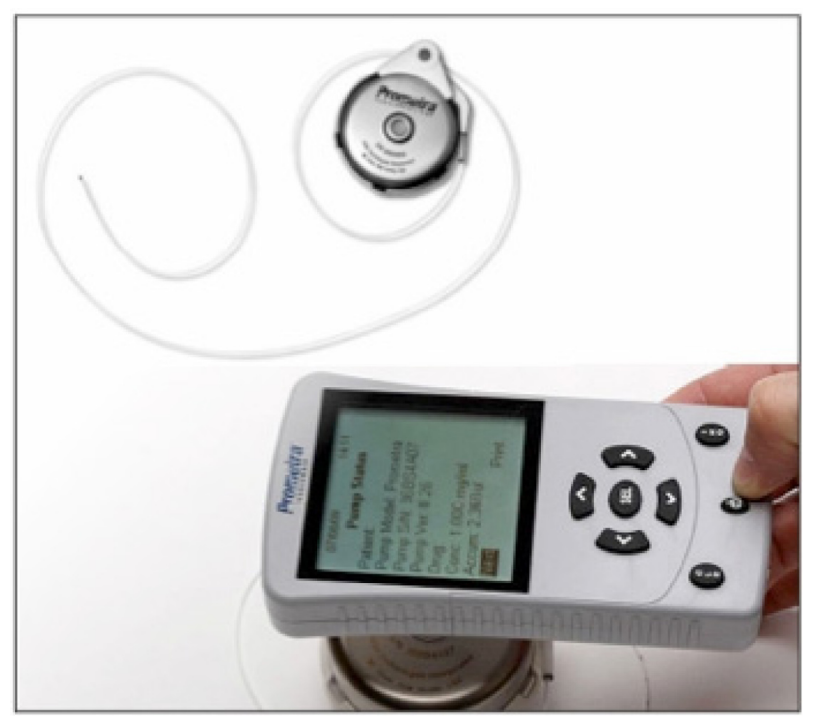

Figure 3 Prometra intrathecal pump and programmer. Images courtesy of Flowonix Medical Inc. 
medication from the syringe during a pump refill, and reducing the risk of inadvertent deposition of medication outside the reservoir into the pump pocket. Moreover, the Medallion may offer a unique pressure sensor at the catheter tip, thus alerting the patient/physician to unanticipated changes in flow. Medtronic has also developed a new intrathecal catheter with improved resistance to kinks and breaks, a sutureless pump connector, and a new catheter anchor.

\section{Device implantation}

IDDS implantation consists of two parts requiring two separate incisions. The first entails placement of the catheter into the intrathecal space of the thoracolumbar region. Typically this incision occurs in the lower back for catheter insertion into the intrathecal space, and catheter adherence to the underlying fascia via anchoring devices (Figure 4). The second part consists of placing the pump/reservoir into the abdominal region. Alternatively, the pump can be placed in the buttock region when abdominal pocket sites are unavailable (ie, multiple ostomies). Several aspects must be considered when deciding where to place the pump reservoir. First, the pump should be placed away from bony landmarks such as the lower thoracic ribs or the iliac crest, to avoid irritation. The implanting physician should discuss whether or not the patient sleeps on his/her side. If so, then the pump should be placed on the contralateral side. In the majority of patients, the pump is surgically placed on either the left or right lower quadrant of the abdomen (Figure 5).

The procedure is carried out in an operating room using sterile technique which includes aseptic skin preparation, sterile drape, and full surgical attire. As placement of the pump is typically located in the abdomen, operating room positioning is usually in the lateral decubitus position to allow the physician access to the potential pump site without patient repositioning intraoperatively, which may increase both surgical time and infection risk. Fluoroscopy is used to identify needle placement for the intrathecal catheter. After the catheter is securely anchored, the surgeon then creates a subcutaneous pocket for the pump reservoir. The depth of the pocket is typically $1.5-2.5 \mathrm{~cm}$ to allow for appropriate needle length during pump refills in the future. Once the pocket is prepared, the

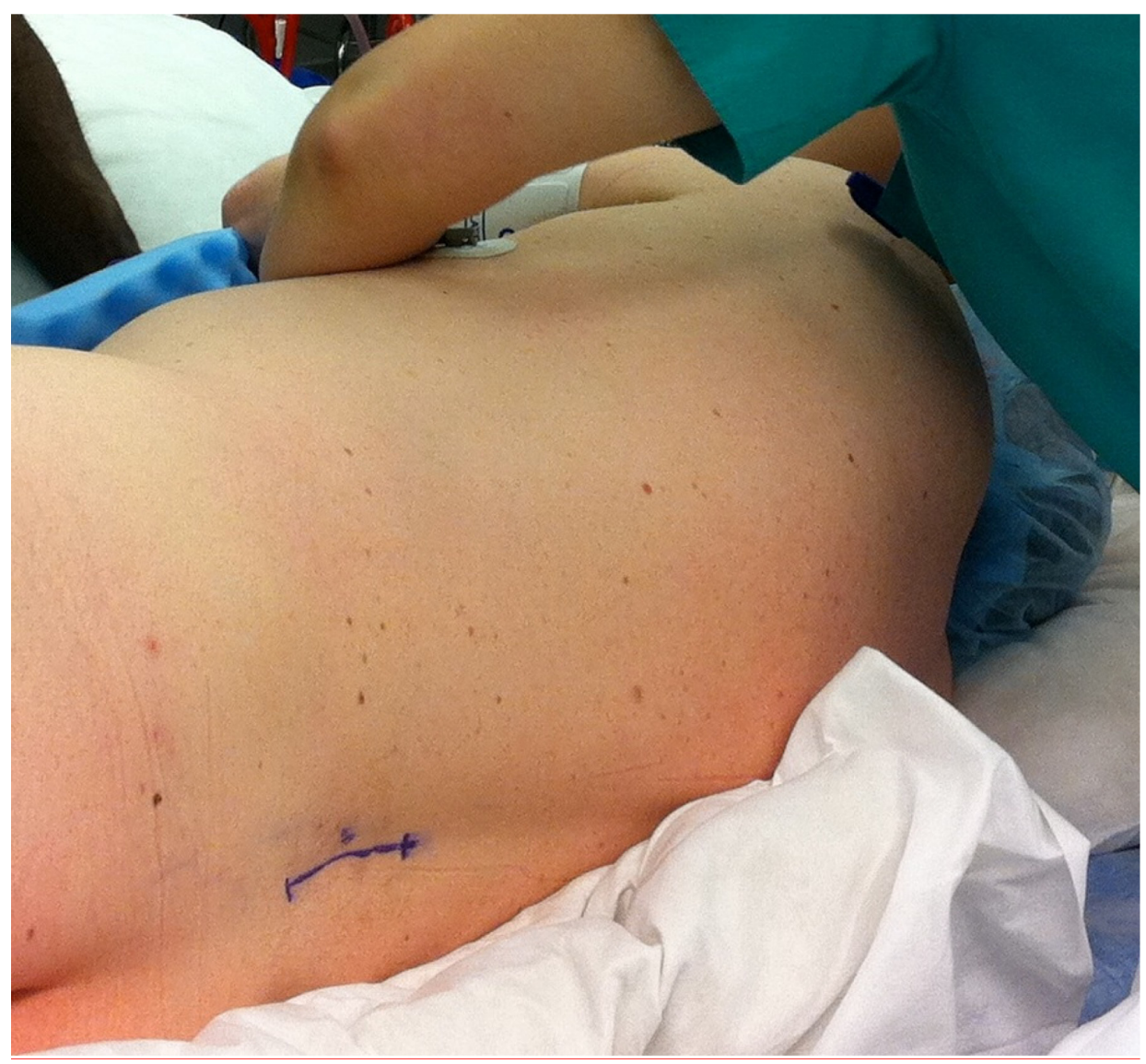

Figure 4 Patient in the lateral decubitus position for intrathecal drug delivery system implantation. The blue surgical mark indicates anticipated lumbar midline incision for intrathecal catheter placement. Photograph courtesy of MMB. 


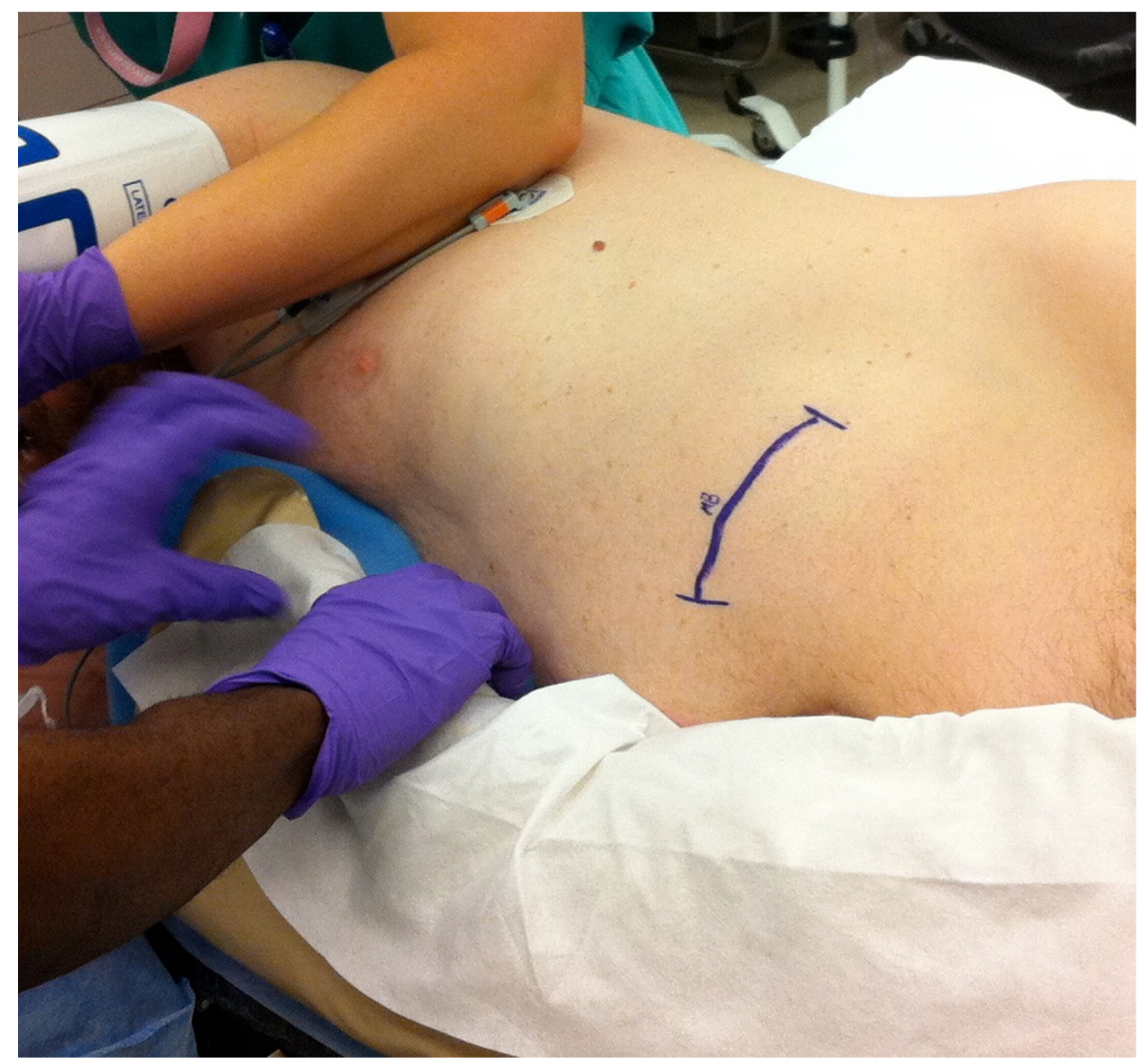

Figure 5 Patient in the lateral decubitus position for implantation of intrathecal drug delivery system. The blue surgical mark indicates anticipated incision in the left lower quadrant for the pump reservoir pocket. Note the importance of cushioning in this position to avoid complications associated with intraoperative nerve compression injuries. Photograph courtesy of MMB.

catheter is tunneled subcutaneously from the posterior spine to the anterior lower abdomen. After securely connecting the catheter to the pump, the pump reservoir is anchored within the pocket and the incision sites are closed.

\section{Pump refill procedure}

FDA regulations require that pumps be refilled at least every 6 months, even if the pump is not completely empty. Refill frequency varies between 1 and 6 months. A kit provided by the pump manufacturer is used during the refill procedure which typically contains an access needle and a template. First, the skin overlying the pump is cleansed in sterile fashion. Next, the template is placed on top of the skin overlying the pump, thus providing an outline that aids the detection of the reservoir fill port. The fill port lies in the center portion of the pump. This port may also be detected using ultrasound (Figure 6) or fluoroscopic guidance. The middle of the port contains a self-sealing silicone septum. The access needle is inserted through the skin and septum. Any remaining solution is withdrawn prior to refilling the pump with the new medication. The amount of withdrawn solution can be compared with the calculated amount based on the previously programmed rate of delivery to ensure that the correct amount of solution has been withdrawn and that the pump is functioning properly. Finally, the new medication is injected through the reservoir fill port followed by pump reprogramming with the new volume and/or new concentration of medication(s).

\section{Complications}

Complications of IDDS therapy can be classified into five categories, ie, mechanical system complications, pharmacological complications and side effects, surgical complications, patient-specific complications, and refill complications.

Mechanical system complications include a variety of errors that can result in either a sudden reduction in medication administration leading to potential withdrawal, or a potential significant overdose leading to hemodynamic instability, respiratory depression, and potentially death. ${ }^{19}$ Mechanical errors can be further categorized beginning 


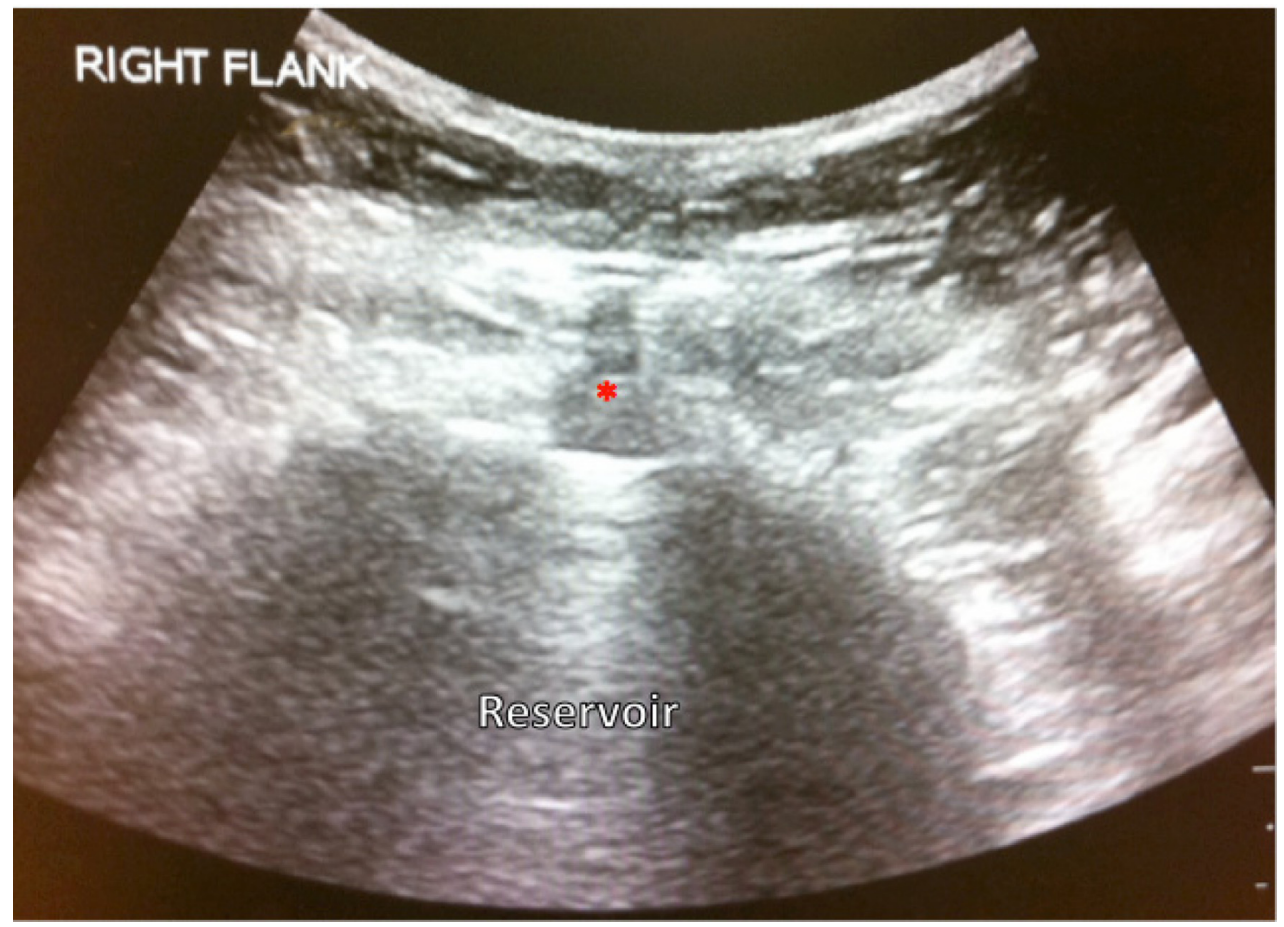

Figure 6 Ultrasound of intrathecal pump. *Indicates the reservoir fill port. Photograph courtesy of MMB.

with the catheter and progressing to the pump: intrathecal catheter displacement causing cerebrospinal fluid leakage and potential local hygroma, intrathecal catheter kinking, catheter pump disconnection leading to leakage of administered agent, loss of pump propellant leading to altered rate of drug delivery, and gear shaft wear/motor stall causing drug underinfusion. ${ }^{24}$ During pump implantation, manually testing for a leak by injecting saline through the catheter access port while occluding the catheter tip distally can aid in detecting a leak at the catheter connection site. After pump implantation, fluoroscopy is commonly used to assess catheter integrity if concerns arise. For example, the physician can aspirate 2-3 $\mathrm{mL}$ of fluid from the accessory port to fully clear the catheter volume in order to avoid delivering a bolus of residual medication contained inside the catheter during assessment. Radiographic contrast can then be injected safely through the accessory port and catheter under fluoroscopic guidance. This permits examination of tip placement or any disruptions in the integrity of the catheter itself. Rarely, a pump may "flip" 180 degrees within the abdomen, thus preventing reservoir access for refills and necessitating surgical intervention. The annual rate for mechanical complications requiring a surgical procedure is reported to be $10.5 \%$, the majority being catheterrelated (65\%) versus pump-related (35\%). ${ }^{25}$ However, catheter complications may decrease with the advent of advanced catheter designs that resist occlusions and breaks.
Pharmacological adverse effects are those inherent to the drugs administered intrathecally. For example, a retrospective evaluation showed that among IDDS-related complications, the most common complication was associated with a patient's adverse reaction to a drug. ${ }^{26}$ Serious complications include anaphylaxis, respiratory depression or arrest, and/or meningitis from a contaminated solution. More specifically, intrathecal opioids may cause centrally mediated respiratory depression, nausea, vomiting, sedation, pruritus, constipation, urinary retention, cognitive impairment, and headache. ${ }^{27}$ Intrathecal ziconotide may cause dizziness, nausea, vomiting, urinary retention, gait imbalance, nystagmus, and confusion. Rarer side effects include psychosis, suicide, and rhabdomyolysis. ${ }^{24}$ Intrathecal baclofen has been shown to potentially cause nausea, vomiting, dizziness, urinary retention, constipation, headache, fatigue, hypotonia, and paresthesias. Life-threatening withdrawal can occur in patients in whom baclofen is abruptly discontinued, and should be treated promptly with oral baclofen supplementation and resumption of baclofen infusion. Side effects of intrathecal clonidine include hypotension, bradycardia, and sedation. Sudden discontinuation of clonidine may cause paradoxical hypertension due to a rebound in sympathetic flow. Local anesthetics can cause autonomic dysfunction, motor impairment, sensory deficits, and potential neurotoxicity, although these are not typically seen at doses of less than $15 \mathrm{mg}$ per day. At higher doses, weakness, fatigue, 
somnolence, paresthesias, and urinary retention have all been observed. ${ }^{27}$ Using device registration and social security analyses, Coffey et al found that patients with noncancer pain treated with intrathecal opioid therapy had an increased mortality $(0.088 \%$ at 3 days after implantation, $0.39 \%$ at 1 month, and $3.89 \%$ at 1 year) compared with similar patients who were using other therapies. While the exact mechanism was not fully elucidated, they hypothesized that respiratory depression due to intrathecal drug overdose or mixed intrathecal and systemic drug interactions could be a possibility. ${ }^{28}$

Surgical complications include bleeding, infection, cerebrospinal fluid leakage, seroma formation, neurological injury, shredded catheters, and malpositioned subcutaneous pockets. ${ }^{24}$ Infection has been shown to be decreased with the use of strict sterile technique, preoperative antibiotic administration, and postoperative monitoring of the incision sites. Most infections do not necessitate removal of the implanted device, but may be treated with appropriate antibiotics after culture. Infections involving the epidural or intrathecal space require immediate removal of the IDDS and administration of intravenous antibiotics. The incidence of superficial or deep infection after placement of IDDS ranges from $2 \%$ to $5 \%$ based on case series with results from more than 100 patients. ${ }^{29-31}$ The risk of deep infections including epidural abscess and meningitis ranges from $0 \%$ to $0.5 \%$ in the same series. Because placement of an IDDS necessitates a postdural puncture for the placement of an intrathecal catheter, persistent cerebrospinal fluid leak can occur in as many as $20 \%$ of patients, including a postdural puncture headache. ${ }^{32}$ Severe symptoms may require an epidural blood patch or surgical closure of the dural tear.

Patient-specific complications include possible hormonal fluctuations with opioid therapy. For instance, follicle-stimulating hormone, luteinizing hormone, testosterone, and growth hormone levels may decrease, inducing symptoms such as fatigue, reduced libido, and sexual dysfunction. Therefore, physicians should monitor serum levels of the aforementioned hormones during intrathecal therapy and treat accordingly. ${ }^{33}$ While a physician may wean a patient from intrathecal opioids under these conditions, patients may not tolerate intrathecal opioid reduction or elimination; therefore, hormone replacement therapy may be more appropriate. ${ }^{18}$

Complications may occur during the pump refill related to either medication error (ie, wrong medication or wrong concentration), reprogramming error (ie, wrong rate), or inadvertent deposition of medication outside the reservoir into the pump pocket, leading to systemic toxicity and potential overdose or death.
Special consideration must be given to catheter tip granulomas. A granuloma is a noninfectious collection of inflammatory cells located at the catheter tip that can increase in size causing spinal cord compression. Although it is rare $(0.04 \%$ incidence at 1 year and $1.16 \%$ after 6 years of therapy), a granuloma can induce devastating neurological complications. ${ }^{34}$ While the etiology is unknown, theories include a reaction to an infused medication, a low-grade infection, or even a reaction to the catheter tip itself. ${ }^{27}$ Previously, the low-flow state of cerebrospinal fluid in the thoracic region was implicated as an increased risk for granuloma formation; however, this has not been scientifically validated. ${ }^{35}$ Granuloma formation has been consistently associated with opioids in the intrathecal space, either alone or with other agents, although there are no case reports of intrathecal inflammatory masses associated with lipophilic agents such as fentanyl or sufentanil. ${ }^{35}$ In preclinical studies, catheter track granuloma formation was noted in three of 25 control drugs and two of 77 control monkeys treated with just saline infusions. ${ }^{36}$ Granulomas are more common in patients with nonmalignant pain versus those with cancer pain and are more prevalent in younger patients. The most frequently reported symptom leading to diagnosis of a granuloma relates to a decrease in therapeutic response/ inadequate pain relief (reported in $33.5 \%$ of cases associated with catheter tip granuloma), or the onset of new pain (eg, thoracic spine pain). ${ }^{37} \mathrm{MRI}$ with gadolinium contrast or computed tomography with myelography can both elucidate granuloma formation, the latter recommended when MRI is contraindicated. The majority of granulomas regress spontaneously when the offending agent is removed from the area. ${ }^{38}$ The 2012 PACC provided an algorithm for the treatment of granulomas. For instance, if the imaging study confirms the presence of a granuloma and the patient reports a significant, progressive neurological deficit, then one should arrange for a surgical consult for possible laminectomy. If there is no neurological deficit, and this is not the first occurrence of a granuloma in this particular patient, then the practitioner should avoid intrathecal opioids and switch to ziconotide. Otherwise, the physician can consider moving the catheter inferiorly in the intrathecal space by $2-3 \mathrm{~cm}$, reducing the drug concentration or dose, or changing to another opioid or ziconotide. If the symptoms resolve, then repeat imaging is recommended in 6 months. However, should the symptoms persist, the catheter should be replaced and the patient should discontinue intrathecal medications/opioids, use oral analgesics in lieu of intrathecal agents, and replace the intrathecal solution with saline. ${ }^{35}$ 


\section{Efficacy}

With respect to cancer pain, a Cochrane review published in 2005 included one randomized controlled trial (RCT) comparing intrathecal morphine with conventional delivery of morphine in patients with cancer pain. ${ }^{39}$ The success rate of intrathecal delivery was $85 \%$ compared with $71 \%$ for that of conventional drug delivery. Furthermore, patients receiving intrathecal morphine survived longer, had fewer side effects, and reported less pain. ${ }^{15}$ In the Cochrane review, there were 28 cohort studies involving 722 patients using intrathecal opioid delivery, namely morphine. Good to excellent analgesic effect was achieved in $87 \%$ of this group. In those patients who fail to achieve sufficient pain relief with intrathecal morphine, one RCT and several cohort studies found that adding bupivacaine was effective in these patients. ${ }^{40}$ Mercadante et al published a prospective observational study on opioid-tolerant cancer patients and the use of intrathecal morphine with levobupivacaine. There was significant improvement in drowsiness and confusion during the first month of intrathecal therapy as well as statistically significant differences in pain intensity at all time intervals studied until death. ${ }^{41}$ In patients with neuropathic pain, clonidine was more effective than placebo (56\% versus $5 \%$ ) in one $\mathrm{RCT},{ }^{42}$ and another RCT found intrathecal ziconotide to relieve pain in patients with cancer or acquired immune deficiency syndrome, although side effects were a major limitation of this drug. ${ }^{43}$ In a study focusing on IDDS and cancer pain, Smith et al published a multicenter RCT including over 200 cancer patients, highlighting the efficacy of IDDS over comprehensive medical management in treating refractory cancer pain. For example, they compared IDDS (opioid \pm bupivacaine) plus medical management (opioids \pm adjuvant medications) with medical management alone. ${ }^{15}$ At short-term, 4-month follow-up, the IDDS group showed a greater reduction in pain and drug toxicity, as well as fewer drug side effects (fatigue and decreased level of consciousness). Importantly, the study also demonstrated an improved 6-month survival in the IDDS group (54\% versus 37\%). Overall, using the United States Preventative Services Task Force criteria for evidence-based medicine, Hayek et al rated intrathecal therapy for cancer pain as level II-2 evidence, with a recommendation strength of moderate when specifically using Guayatt's criteria. ${ }^{44}$

The efficacy of IDDS for the treatment of chronic noncancer pain is less clear and robust as that for cancer pain. For instance, in a systematic review, Patel et al reported level II-3 or level III (limited) evidence for the use of intrathecal infusion systems for chronic noncancer pain due to the paucity of literature, lack of quality evidence, and lack of randomized trials. ${ }^{45}$ Moreover, a 2013 review of the literature identified 28 studies of which only seven nonrandomized studies met the inclusion criteria for methodological quality assessment, and no randomized trials met the inclusion requirements. Based on these data, Falco et al stated that the evidence for intrathecal infusion systems for long-term management of chronic noncancer pain was limited based on observational studies. ${ }^{46}$

The data on intrathecal baclofen as an antispasmodic, however, are more compelling. In fact, intrathecal baclofen has been used to treat spasticity for almost 30 years. In a 2006 Cochrane review, Taricco et al concluded that only intrathecal baclofen proved significantly effective in treating spinal cord injury-induced spasticity. ${ }^{47}$ Further, two studies totaling 14 spinal cord injury patients showed that intrathecal baclofen significantly reduced spasticity (eg, Ashworth score and performance of activities of daily living) without any adverse effects when compared with placebo. ${ }^{48,49}$

\section{Cost-effectiveness}

With the rising cost of health care, there has been intense scrutiny regarding the cost effectiveness of interventional therapies. There have been several studies published examining the cost-effectiveness of intrathecal therapy, and most have examined chronic nonmalignant pain. Review of the available evidence demonstrates that although there is an initial increased cost associated with intrathecal drug delivery, the maintenance cost over time is significantly lower than with conventional medical management. For example, de Lissovoy et al compared intrathecal morphine with medical management for patients with failed back surgery syndrome and showed that IDDS therapy was cost-effective at $12-22$ months. ${ }^{50} \mathrm{~A}$ cost analysis study by Kumar et al comparing intrathecal therapy versus conventional pain therapy for failed back surgery syndrome patients showed that the break-even point occurred at 28 months. ${ }^{51}$ In 2013, the medical cost impact of intrathecal drug delivery for noncancer pain was studied in a retrospective database review of 555 patients with noncancer pain who received an IDDS between 2006 and 2009. ${ }^{52}$ In the first year following implantation, IDDS was cumulatively $\$ 17,317$ more expensive than conventional pain therapy. However, the authors found that the financial break-even point occurred soon after the second year of implantation. Importantly, the lifetime analysis indicated that IDDS resulted in a net savings of $\$ 3,111$ compared with conventional pain therapy. IDDS was also compared with epidural morphine delivery using an external pump. This study demonstrated that the costs of therapy were equivalent 
to a break-even point of approximately 3 months. ${ }^{53}$ Further, Mueller-Schwefe et al concluded that, for cancer patients, intrathecal drug delivery is most cost-effective between 3 and 6 months. ${ }^{54}$ Most recently, Brogan et al published a cost utilization analysis of intrathecal therapy specific to cancer pain. ${ }^{55}$ In this retrospective review of 36 patients with intractable cancer pain who survived beyond 4 weeks, they concluded that intrathecal drug delivery was more cost beneficial within 6 months of treatment. However, cost-effectiveness was only seen in the high cost conventional group (ie, using rapid-acting fentanyl products) rather than the low cost conventional group. The results were similar to those published by Mueller-Schwefe et al, suggesting that IDDS becomes cost-effective more quickly for cancer patients than for noncancer patients. This may be in part due to the dynamic changes associated with cancer pain and its progression compared with that of chronic nonmalignant pain.

\section{Conclusion}

Since morphine was first injected into the spinal fluid to treat cancer pain in 1979, there have been innovations in IDDS as well as the breadth of medications delivered to the intrathecal space for control of pain and spasticity. Delivering medications intrathecally allows for significantly reduced doses compared with oral therapy, along with a reduction in the adverse effects associated with oral or parenteral delivery of analgesics. Recent consensus guidelines provide lines of therapy with agents such as morphine, ziconotide, clonidine, and bupivacaine based on nociceptive, neuropathic, or mixed pain conditions. Most experts believe that IDDS can be quite effective for a smaller subset of patients with cancer, noncancer, and spasticityinduced pain. Further, trialing patients prior to implantation is generally recommended, but may be less necessary for patients suffering from cancer pain. The data emphasize the value of intrathecal therapy for cancer pain in terms of pain relief, reduction in adverse effects, and cost-effectiveness. The evidence is less clear for long-term relief in noncancer pain other than spasticity, although the cost-effectiveness data support its use within approximately 12-24 months compared with traditional therapies. Implanting physicians should be mindful of the need to monitor fluctuations in selected serum hormones, especially with intrathecal opioids as well as the potential for development of granuloma. Studies in progress with novel intrathecal agents coupled with advanced IDDS technology offer promise for more complete pain relief, enhanced safety, and better long-term outcomes in terms of quality of life.

\section{Disclosure}

MMB has no financial interests or disclosures regarding the content of this paper. PJC has no financial interest in the content of the paper. PJC has received grant support from Medtronic, served on advisory boards for Ameritox and Purdue Pharma, and receives support for media work via Algiatry, LLC.

\section{References}

1. Levy MH. Pain control in patients with cancer. Oncology. 1999; 13(5 Suppl 2):9-14.

2. Cherny NI, Foley KM. Nonopioid and opioid analgesic pharmacotherapy of cancer pain. Otolaryngol Clin North Am. 1997;30:279-306.

3. Pappagallo M. Incidence, prevalence, and management of opioid bowel dysfunction. Am J Surg. 2001;182(Suppl 5A):11S-18S.

4. Lamer T. Treatment of cancer-related pain: when orally administered medications fail. Mayo Clin Proc. 1994;69:473-480.

5. Bier A. [Attempts over Cocainisirung of the Ruckenmarkers]. Langenbecks Arch Klin Chir Ver Dtsch Z Chir. 1899;51:361-369. German.

6. Onofrio BM, Yaksh TL, Arnold PG. Continuous low-dose intrathecal morphine administration in the treatment of chronic pain of malignant origin. Mayo Clin Proc. 1981;56:516-520.

7. Pert CB, Snyder SH. Opiate receptor: demonstration in nervous tissue. Science. 1973;179:1011-1014.

8. Blackshear PJ, Rohde TD, Prosl F, Buchwald H. The implantable infusion pump: a new concept in drug delivery. Med Prog Technol. 1979;30:146-149.

9. Wang JK, Nauss LA, Thomas JE. Pain relief by intrathecally applied morphine in man. Anesthesiology. 1979;50:149-151.

10. Wallace M, Yaksh TL. Long-term spinal analgesic delivery: a review of the preclinical and clinical literature. Reg Anesth Pain Med. 2000;25: $117-157$.

11. Prager JP. Neuraxial medication delivery: the development and maturity of a concept for treating chronic pain of spinal origin. Spine. 2002;27:2593-2605.

12. Deer TR, Prager J, Levy R, et al. Polyanalgesic Consensus Conference 2012: recommendations on trialing for intrathecal (intraspinal) drug delivery: report of an interdisciplinary expert panel. Neuromodulation. 2012;15:436-464.

13. Turner JA, Sears JM, Loeser JD. Programmable intrathecal opioid delivery systems for chronic noncancer pain: a systematic review of effectiveness and complications. Clin J Pain. 2007;23:180-195.

14. Brown J, Klapow J, Doleys D, Lowery D, Tutak U. Disease specific and generic health outcomes: a model for the evaluation of long-term intrathecal opioid therapy in noncancer low back pain patients. Clin J Pain. 1999;15:122-131.

15. Smith TJ, Staats PS, Deer T, et al. Randomized clinical trial of an implantable drug delivery system compared with comprehensive medical management for refractory cancer pain, drug related toxicity, and survival. J Clin Oncol. 2002;20:4040-4049.

16. Rauck RL, Cherry D, Boyer MF, Kosek P, Dunn J, Alo K. Longterm intrathecal opioid therapy with a patient-activated, implanted delivery system for the treatment of refractory cancer pain. J Pain. 2003;4: 441-447.

17. Christo PJ, Mazloomdoost D. Interventional pain treatments for cancer pain. Ann N Y Acad Sci. 2008;1138:299-328.

18. Deer TR, Prager J, Levy R, et al. Polyanalgesic Consensus Conference 2012: Recommendations for the management of pain by intrathecal (intraspinal) drug delivery: report of an interdisciplinary expert panel. Neuromodulation. 2012;15(5):436-466.

19. Deer TR, Smith HS, Burton AW, et al. Comprehensive consensus based guidelines on intrathecal drug delivery systems in the treatment of pain caused by cancer pain. Pain Physician. 2011;14:E283-E312. 
20. Smith TJ, Coyne PJ. How to use implantable intrathecal drug delivery systems for refractory cancer pain. J Support Oncol. 2003;1: 73-76.

21. Hassenbusch SJ, Stanton-Hicks M, Covington EC, Walsh JG, Guthrey DS. Long-term intraspinal infusions of opioids in the treatment of neuropathic pain. J Pain Symptom Manage. 1995;10:527-543.

22. Ilias W, le Polain B, Buchser E, Demartini L; oPTiMa Study Group. Patient-controlled analgesia in chronic pain patients: experience with a new device designed to be used with implanted programmable pumps. Pain Pract. 2008;8:164-170.

23. Rauck R, Deer T, Rosen S, et al. Accuracy and efficacy of intrathecal administration of morphine sulfate for treatment of intractable pain using the Prometra programmable pump. Neuromodulation. 2010;13: 102-108.

24. Upadhyay SP, Mallick PN. Intrathecal drug delivery system (IDDS) for cancer pain management: a review and updates. Am J Hosp Palliat Care. 2012;29:388-398.

25. Steams L, Boortz-Marx R, Du Pen S, et al. Intrathecal drug delivery for the management of cancer pain: a multidisciplinary consensus of best clinical practices. J Support Oncol. 2005;3:399-408.

26. Bhatia G, Lau ME, Gulur P, Koury KM. Intrathecal drug delivery (ITDD) systems for cancer pain. Version 3. F1000Res. 2013;2:96.

27. Britishpainsociety.org. Intrathecal drug delivery for the management of pain and spasticity in adults; recommendations for best clinical practice. The British Pain Society; 2008. Available from: http://www. britishpainsociety.org/. Accessed March 7, 2014.

28. Coffey RJ, Owens ML, Broste SK, et al. Mortality associated with implantation and management of intrathecal opioid drug infusion systems to treat noncancer pain. Anesthesiology. 2009;111:881-891.

29. Kumar K, Nath R, Wyant GM. Treatment of chronic pain by epidural spinal cord stimulation: a 10-year experience. J Neurosurg. 1991;75: 402-407.

30. Lang P. The treatment of chronic pain by epiduralspinal cord stimulationa 15 year follow up; present status. Axon. 1997;18:71-73.

31. Meglio M, Cioni B, Rossi GF. Spinal cord stimulation in management of chronic pain. A 9-year experience. J Neurosurg. 1989;70:519-524.

32. Knight KH, Brand FM, Mchaourab AS, Veneziano G. Implantable intrathecal pumps for chronic pain: highlights and updates. Croat Med J. 2007;48:22-34.

33. Deer TR, Prager J, Levy R, et al. Polyanalgesic Consensus Conference 2012: recommendations to reduce morbidity and mortality in intrathecal drug delivery in the treatment of chronic pain. Neuromodulation. 2012;15:436-464.

34. Yaksh TL, Hassenbusch S, Burchiel K, Hildebrand KR, Page LM, Coffey RJ. Inflammatory masses associated with intrathecal drug infusion: a review of preclinical evidence and human data. Pain Med. 2002;3:299-312.

35. Deer TR, Prager J, Levy R, et al. Polyanalgesic Consensus Conference 2012: consensus on diagnosis, detection, and treatment of catheter-tip granulomas (inflammatory masses). Neuromodulation. 2012;15: 483-495.

36. Butt MT. Morphologic changes associated with intrathecal catheters for direct delivery to the central nervous system in preclinical studies. Toxicol Pathol. 2011;39:213-219.

37. Professional.medtronic.com. Medtronic Neuromodulation: intrathecal distal end catheter occlusions as a result of $\mathrm{pH}$ and salt concentration gradients between delivery solution and cerebrospinal fluid (CSF). Available from: https://professional.medtronic.com/wcm/groups/mdtcom_sg/@ mdt/@neuro/documents/documents/inflammatory_mass_letter.pdf. Accessed June 1, 2014.

Journal of Pain Research

\section{Publish your work in this journal}

The Journal of Pain Research is an international, peer-reviewed, open access, online journal that welcomes laboratory and clinical findings in the fields of pain research and the prevention and management of pain. Original research, reviews, symposium reports, hypothesis formation and commentaries are all considered for publication.

Submit your manuscript here: http://www.dovepress.com/journal-of-pain-research-journal
38. Jourdain V, Cantin L, Prud'Homme M, Fournier-Gosselin M. Intrathecal morphine therapy-related granulomas: faster to grow than thought. Neuromodulation. 2009;12:164-168.

39. Ballantyne JC, Carwood CM. Comparative efficacy of epidural, subarachnoid, and intracerebroventricular opioids in patients with pain due to cancer. Cochrane Database Syst Rev. 2005;1:CD005178.

40. Vissers KC, Besse K, Wagemans M, et al. Pain in patients with cancer. Pain Pract. 2011;11:453-475.

41. Mercadante S, Intravaia G, Villari P, et al. Intrathecal treatment in cancer patients unresponsive to multiple trials of systemic opioids. Clin J Pain. 2007;23:793-798.

42. Landelijke richtlijnwerkgroep Pijn bij kanker. Pijn bij kanker. Landelijke richtlijn. In: Landelijke richtlijnwerkgroep Pijn bij kanker. 2008:1-168. ISBN 978-90-8523-168-4.

43. Staats PS, Yearwood T, Charapata SG, et al. Intrathecal ziconotide in the treatment of refractory pain in patients with cancer or AIDS: a randomized controlled trial. JAMA. 2004;291:63-70.

44. Hayek SM, Deer TR, Pope JE, Panchal SJ, Patel VB. Intrathecal therapy for cancer and noncancer pain. Pain Physician. 2011;14:219-248.

45. Patel VB, Manchikanti L, Singh V, Schultz DM, Hayek SM, Smith HS. Systematic review of intrathecal infusion systems for long-term management of chronic non-cancer pain. Pain Physician. 2009;12:345-360.

46. Falco FJ, Patel VB, Hayek SM, et al. Intrathecal infusion systems for long-term management of chronic non-cancer pain: an update of assessment of evidence. Pain Physician. 2013;16(Suppl 2):SE185-SE216.

47. Taricco M, Pagliacci MC, Telaro E, Adone R. Pharmacological interventions for spasticity following spinal cord injury: results of a Cochrane systematic review. Eura Medicophys. 2006;42:5-15.

48. Penn RD, Savoy SM, Corcos D, Latash M, Gottlieb G, Parke B et al. Intrathecal baclofen for severe spinal spasticity. $N$ Engl J Med. 1989;320:1517-1521.

49. Hugenholts H, Nelson RF, Dehoux E, Bickerton R. Intrathecal baclofen for intractable spinal spasticity-a double blind crossover study in eight patients. Can J Neurol Sci. 1992;19:188-195.

50. de Lissovoy G, Brown RE, Halpern M, Hassenbusch SJ, Ross E. Cost-effectiveness of longterm intrathecal morphine therapy for pain associated with failed back surgery syndrome. Clin Ther. 1997;19: 96-112.

51. Kumar K, Hunter G, Demeria DD. Treatment of chronic pain by using intrathecal drug therapy compared with conventional pain therapies: a cost-effectiveness analysis. $J$ Neurosurg. 2002;97:803-810.

52. Guillemette S, Witzke S, Leier J, Hinnenthal J, Prager JP. Medical cost impact of intrathecal drug delivery for noncancer pain. Pain Med. 2013;14:504-515.

53. Bedder MD, Burchiel K, Larson A. Cost analysis of two implantable narcotic delivery systems. J Pain Symptom Manage. 1991;6:368-373.

54. Mueller-Schwefe G, Hassenbusch SJ, Reig E. Cost effectiveness of intrathecal therapy for pain. Neuromodulation. 1999;2:77-87.

55. Brogan SE, Winter NB, Abiodun A, Safarpour R. A cost utilization analysis of intrathecal therapy for refractory cancer pain: identifying factors associated with cost benefit. Pain Med. 2013;14:478-486.

\section{Dovepress}

The manuscript management system is completely online and includes a very quick and fair peer-review system, which is all easy to use. Visit http://www.dovepress.com/testimonials.php to read real quotes from published authors. 